07

\title{
Термическая стабильность несплавных омических контактов к гетероструктурам AIGaN/GaN
}

\author{
(С А.Ю. Павлов, В.Ю. Павлов, Д.Н. Слаповский
}

Институт сверхвысокочастотной полупроводниковой электроники РАН, Москва

E-mail: p.alex.ur@yandex.ru

Поступило в Редакцию 14 июня 2017 г.

Представлены результаты исследования деградации несплавных омических контактов с эпитаксиально-доращиваемым сильнолегированным GaN к гетероструктурам с двумерным электронным газом (ДЭГ). Исследовалось изменение значения относительного удельного контактного сопротивления при температуpax до $600^{\circ} \mathrm{C}$ для металлизаций $\mathrm{Ti} / \mathrm{Pd} / \mathrm{Au}, \mathrm{Cr} / \mathrm{Au}$ и $\mathrm{Cr} / \mathrm{Pd} / \mathrm{Au}$. Наилучшую стойкость к температурным воздействиям показал состав металлизации $\mathrm{Cr} / \mathrm{Pd} / \mathrm{Au}$, сопротивление которого уменьшалось при рабочих температурах $400^{\circ} \mathrm{C}$. Впервые продемонстрировано, что наибольший вклад в увеличение значения контактного сопротивления к ДЭГ при нагреве выше $400^{\circ} \mathrm{C}$ вносит сопротивление структуры металл-полупроводник $\left(\mathrm{Cr} / \mathrm{Pd} / \mathrm{Au}-n^{+}-\mathrm{GaN}\right)$, при этом при температурах $400^{\circ} \mathrm{C}$ и выше происходит уменьшение значения сопротивления между сильнолегированным $\mathrm{GaN}$ и ДЭГ.

DOI: 10.21883/PJTF.2017.22.45267.16917

Гетероструктуры AlGaN/GaN постепенно занимают место в сверхвысокочастотной (СВЧ) полупроводниковой электронике, заменяя элементную компонентную базу, сформированную на гетероструктурах на основе GaAs, как материал с большой шириной запрещенной зоны и высокой концентрацией основных носителей заряда, обеспечивающий работу приборов на его основе при бо́льших температурах и с большей выходной мощностью. В России продемонстрирована принципиальная возможность создания отечественной элементной компонентной базы диапазона частот до $100 \mathrm{GHz}$ на нитридных структурах [1,2]. При изготовлении данных СВЧ монолитных интегральных схем (МИС) были использованы несплавные омические контакты, интерес к которым 
возрос в связи с необходимостью увеличения рабочего диапазона частот схем. Несплавные омические контакты за счет отсутствия высокотемпературной обработки после нанесения состава металлизации контакта позволяют сохранить гладкий рельеф и ровную границу омических контактов полевого транзистора в схеме. Это позволяет формировать метки для электронно-лучевой литографии в одном слое с металлизацией контактов, что обеспечивает лучшее вписывание полевого транзистора между омическими контактами полевого транзистора, расстояние между которыми может составлять несколько микрометров. При этом удельное контактное сопротивление несплавных омических контактов в несколько раз меньше, чем для сплавных омических контактов, что является дополнительным плюсом их внедрения [3].

Использование несплавных методов формирования омических контактов к гетероструктурам $\mathrm{AlGaN} / \mathrm{GaN}$ требует дополнительных исследований для оценки изменения их характеристик в зависимости от внешних факторов, таких как температура. В процессе изготовления приборов и их работы контакт металл-полупроводник греется и может менять свои свойства. При сплавной технологии формирования омических контактов они подвергаются высокотемпературной обработке и обладают большей термостабильностью, чем несплавные. В качестве контактной металлизации без термической обработки в несплавных методах используют композиции $\mathrm{Ti} / \mathrm{Au}$ и $\mathrm{Cr} / \mathrm{Au}$. Для предотвращения миграции золота через контактный слой $\mathrm{Ti}(\mathrm{Cr})$ в полупроводник, происходящей при нагреве, в состав омического контакта вводят слой платины или палладия, обеспечивающий лучшую термостабильность несплавных омических контактов до температур $350-400^{\circ} \mathrm{C}$. Использование в качестве контакта к сильнолегированному GaN состава металлизации традиционной сплавной композиции Ti/Al/Ti/Au после осаждения позволяет получать низкое значение удельного контактного сопротивления, но при нагреве данного состава до $300-400^{\circ} \mathrm{C}$ появляется неомичность контакта металл-полупроводник, характеризующаяся нелинейной вольт-амперной характеристикой $[4,5]$. Поскольку СВЧ МИС в процессе изготовления проходят технологические операции с температурой процесса $300-350^{\circ} \mathrm{C}$, использование состава металлизации традиционной сплавной композиции $\mathrm{Ti} / \mathrm{Al} / \mathrm{Ti} / \mathrm{Au}$ без сплавления не имеет смысла.

В связи с этим появилась задача определить диапазон температур использования несплавных омических контактов разного состава к

7 Письма в ЖТФ, 2017, том 43, вып. 22 
эпитаксиально-доращиваемому сильнолегированному GaN под металлизацией омического контакта, селективно осажденного через предварительно сформированную диэлектрическую маску в процессе изготовления СВЧ МИС и их эксплуатации. Необходимо оценить деградацию несплавных омических контактов к гетероструктурам AlGaN/GaN при температурах до $400^{\circ} \mathrm{C}$ и выше за счет оценки изменения удельного сопротивления омического контакта к двумерному электронному газу (ДЭГ) гетероструктуры.

Для исследования термической стабильности несплавных омических контактов к гетероструктурам $\mathrm{AlGaN} / \mathrm{GaN}$ с разным составом металлизации омического контакта применялись структуры, выращенные на подложках сапфира методом химического осаждения из газовой фазы с использованием металлоорганических соединений без защитного слоя, с открытым барьером. Оценка влияния термического воздействия на сопротивление омического контакта проводилась с помощью формируемых на гетероструктурах тестовых элементов, реализующих метод длинной линии (LTLM - linear transmission line method) и представляющих собой набор контактных площадок шириной $20 \mu \mathrm{m}$, расположенных друг от друга на расстоянии, различающемся в 2 раза, зазоры между контактными площадками составляли: 2, 4, 8 и $16 \mu \mathrm{m}$. Для получения тестовых элементов необходимо выполнение следующего порядка технологических операций [6]. Первоначально на гетероструктуpax $\mathrm{AlGaN} / \mathrm{GaN}$ формируется приборная изоляция, плазмохимическим травлением через фоторезистивную маску удаляются активные слои гетероструктуры в хлорсодержащей среде до глубины порядка $70 \mathrm{~nm}$. Затем формируется диэлектрическая маска со вскрытыми окнами в местах контакта металлической композиции к полупроводнику, через которую перед ростом сильнолегированного GaN проводится плазмохимическое травление гетероструктуры в хлорсодержащей плазме до уровня или ниже уровня ДЭГ [7]. Методом аммиачной молекулярнолучевой эпитаксии осуществляется селективный рост сильнолегированного $\mathrm{GaN}$ на гетероструктуре с изготовленной маской; таким образом, в местах будущего омического контакта формируется сильнолегированный полупроводник. Удаление диэлектрической маски происходит жидкостным химическим травлением в растворе на основе плавиковой кислоты. На гетероструктуру с участками сильнолегированного $\mathrm{GaN}$ через двухслойную фоторезистивную маску методом вакуумного тер-

Письма в ЖТФ, 2017, том 43, вып. 22 


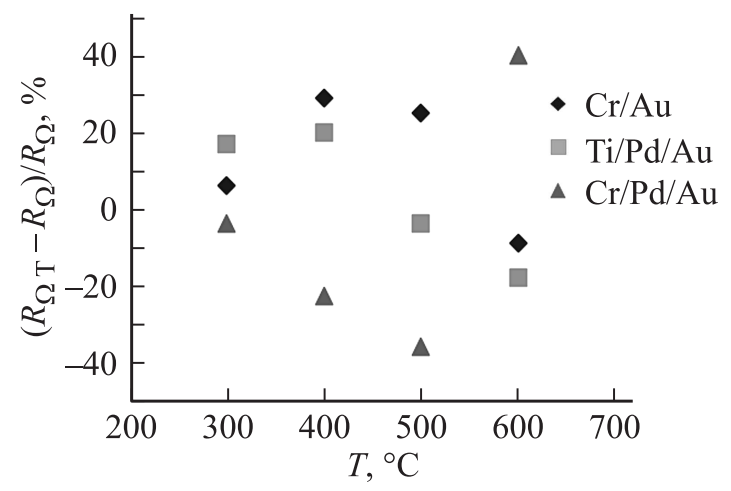

Рис. 1. Зависимость изменения удельного контактного сопротивления $\left(R_{\Omega T}\right)$, измеренного после нагрева, относительно первоначального $\left(R_{\Omega}\right)$ от температуры.

мического (резистивного) нанесения без нагрева осаждается контактная металлизация необходимого состава.

Для сравнения термостабильности несплавных омических контактов к гетероструктурам $\mathrm{AlGaN} / \mathrm{GaN}$ с доращиванием сильнолегированного $\mathrm{GaN}$ были исследованы следующие составы металлизации: $\mathrm{Ti} / \mathrm{Pd} / \mathrm{Au}$, $\mathrm{Cr} / \mathrm{Au}$ и $\mathrm{Cr} / \mathrm{Pd} / \mathrm{Au}$. Титан и хром выбраны в качестве контактных слоев металлизации к полупроводнику, палладий введен как диффузионный барьер, a $\mathrm{Au}$ - как защитный химически неактивный верхний контактный слой к металлизации омического контакта.

Образцы с тестовыми структурами и разными составами металлизаций подвергались одновременному нагреву в установке быстрого термического отжига STE RTA79 от 300 до $600^{\circ} \mathrm{C}$ с шагом $100^{\circ} \mathrm{C}$ в течение $15 \mathrm{~min}$ в инертной среде азота. До и после термического воздействия на каждом образце оценивалось удельное контактное сопротивление омических контактов для определения его изменения относительно первоначального значения. Поскольку образцы изготавливались на разных пластинах и брались из разных частей пластины, то оценивалось относительное изменение удельного контактного сопротивления каждого образца. Для каждого температурного воздействия использовался ранее не подвергавшийся нагреву образец. Результаты в виде зависимости изменения удельного контактного сопротивления

7* Письма в ЖТФ, 2017, том 43, вып. 22 
относительно первоначального значения от температуры представлены на рис. 1. Из зависимостей видно, что значения удельных контактных сопротивлений омических контактов с составами металлизации $\mathrm{Cr} / \mathrm{Au}$ и $\mathrm{Ti} / \mathrm{Pd} / \mathrm{Au}$ при нагреве до $400^{\circ} \mathrm{C}$ увеличиваются относительно измеренного сопротивления при комнатной температуре, а омических контактов с составом $\mathrm{Cr} / \mathrm{Pd} / \mathrm{Au}$ практически не изменяются. Но при нагреве выше $400^{\circ} \mathrm{C}$ мы наблюдаем обратную картину: значения сопротивления для металлизаций всех составов уменьшаются.

При измерении удельного контактного сопротивления методом длинной линии общее измеряемое контактное сопротивление к каналу гетероструктуры включает в себя следующие составляющие $R_{\Omega}$ : сопротивление металл-полупроводник $\mathrm{Cr} / \mathrm{Pd} / \mathrm{Au}-n^{+} \mathrm{GaN}\left(R_{c}\right)$, сопротивление сильнолегированного эпитаксиально-доращиваемого полупроводника $\mathrm{GaN}\left(R_{\mathrm{GaN}}\right)$ и сопротивление между сильнолегированным $\mathrm{GaN}$ и двумерным электронным газом $\left(R_{2 \mathrm{DEG}}\right)$, что схематически показано на рис. 2. Для оценки вклада каждого сопротивления в итоговое удельное контактное сопротивление несплавного омического контакта к гетероструктуре $\mathrm{AlGaN} / \mathrm{GaN}$ в тестовый модуль образца дополнительно были введены аналогичный тест метода длинной линии к сильнолегированному $\mathrm{GaN}\left(R_{c}\right)$, эпитаксиально-доращиваемому на буферный слой гетероструктуры, и тест удельного сопротивления сильнолегированного полупроводника $\left(R_{\mathrm{GaN}}=100 \Omega / \square\right)$. Таким образом, при вычитании из измеренного значения общего удельного контактного сопротивления к гетероструктуре $\mathrm{AlGaN} / \mathrm{GaN}$ измеренного значения удельного контактного сопротивления к сильнолегированному GaN оценивается удельное контактное сопротивление к двумерному электронному газу гетероструктуры $\left(R_{2 \mathrm{DEG}} \approx R_{\Omega}-R_{c}[\Omega \cdot \mathrm{mm}]\right)$. Используя данные тесты, можно оценить изменение каждого сопротивления при термическом воздействии на несплавной омический контакт и увидеть, какое из составляющих сопротивлений наиболее деградирует при нагреве. Для термического воздействия на данные тесты использовалась контактная металлизация $\mathrm{Cr} / \mathrm{Pd} / \mathrm{Au}$. Образцы с тестами нагревались при температурах $300,400,500,600^{\circ} \mathrm{C}$ в течение $15 \mathrm{~min}$ в среде азота аналогично первому эксперименту. После каждого нагрева измерялись удельные контактные сопротивления $R_{\Omega}$ и $R_{c}$. Результаты измерений представлены на рис. 3. В результате проведенного эксперимента видно, что при нагреве несплавных омических контактов с эпитаксиальнодоращиваемым сильнолегированным $\mathrm{GaN}$ происходит рост удель-

Письма в ЖТФ, 2017, том 43, вып. 22 

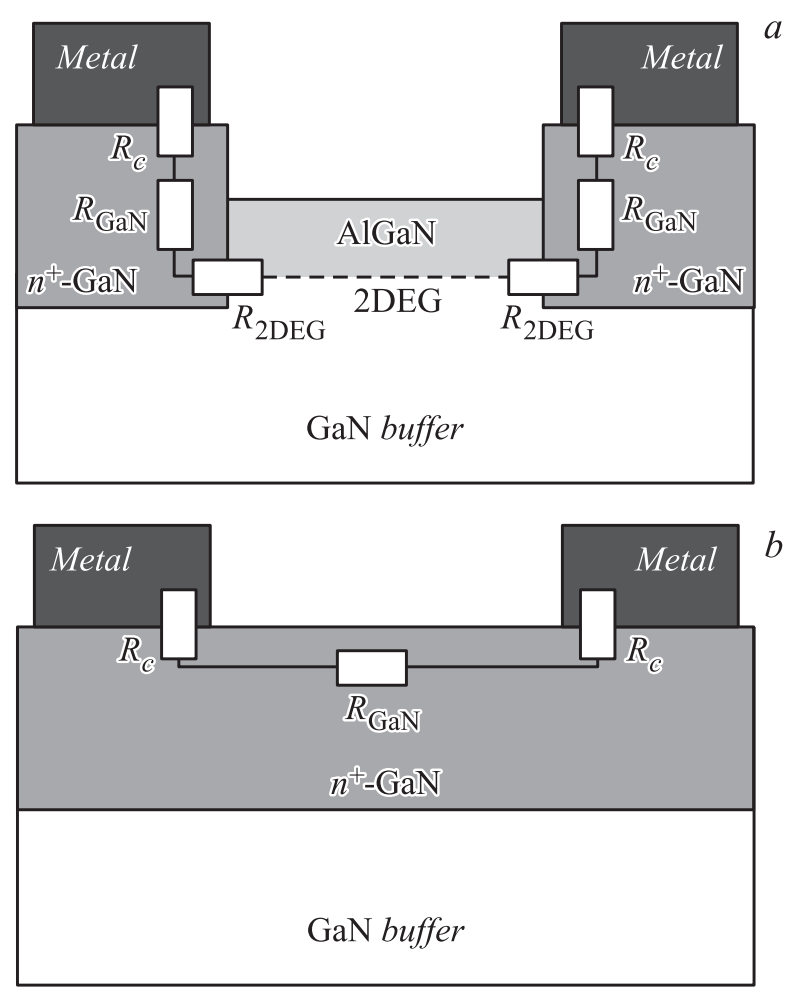

Рис. 2. Схема тестового элемента для определения значения удельного контактного сопротивления к гетероструктуре $\mathrm{AlGaN} / \mathrm{GaN}$ (a) и сильнолегированному $\mathrm{GaN}(b)$ в разрезе. $R_{c}-$ сопротивление металлсильнолегированный $\mathrm{GaN}, R_{\mathrm{GaN}}$ - сопротивление сильнолегированного $\mathrm{GaN}$, $R_{2 \mathrm{DEG}}$ - сопротивление между сильнолегированным $\mathrm{GaN}$ и двумерным электронным газом.

ного контактного сопротивления структуры металл-полупроводник $\mathrm{Cr} / \mathrm{Pd} / \mathrm{Au}-n^{+} \mathrm{GaN}\left(R_{c}\right)$, что согласуется с экспериментальными данными из зарубежной литературы $[4,5]$ и объясняется миграцией золота при нагреве к границе металл-полупроводник с последующей диффузией золота в $\mathrm{GaN}$. При этом измеряемое удельное сопротивление на тесте омического контакта к гетероструктуре с ДЭГ уменьшалось, что

Письма в ЖТФ, 2017, том 43, вып. 22 


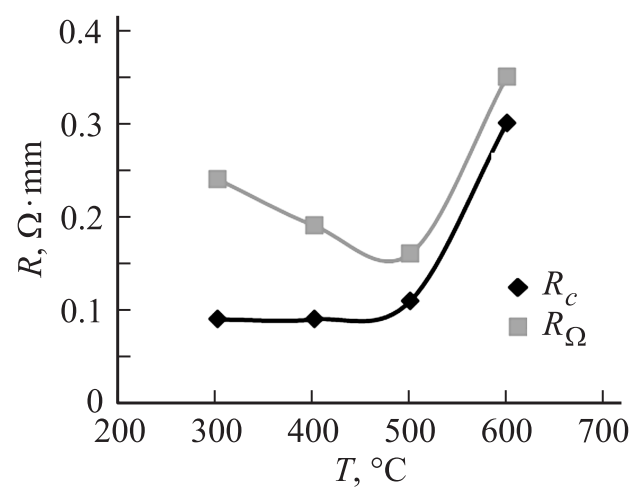

Рис. 3. Зависимость удельного контактного сопротивления к сильнолегированному $\mathrm{GaN} R_{c}$ и к гетероструктуре $\mathrm{AlGaN} / \mathrm{GaN}\left(R_{\Omega}\right)$ от температуры.

свидетельствует об уменьшении сопротивления между сильнолегированным GaN и ДЭГ, так как в тех же условиях и на том же образце сопротивление металл-полупроводник увеличивалось. Сопротивление между сильнолегированным GaN и ДЭГ при температуре отжига $300^{\circ} \mathrm{C}$ составляло около $0.15 \Omega \cdot \mathrm{mm}$, а после отжига при температурах выше $500^{\circ}-0.05 \Omega \cdot \mathrm{mm}$. При больших значениях сопротивления между сильнолегированными $\mathrm{GaN}$ и ДЭГ его можно минимизировать за счет предварительного нагрева гетероструктуры со сформированным сильнолегированным $\mathrm{GaN}$ перед операцией формирования контактной металлизации несплавных омических контактов. По зарубежным данным теоретический предел сопротивления к ДЭГ для GaN-HEMT составляет менее $0.02 \Omega \cdot \mathrm{mm}[8]$.

Таким образом, в результате термических воздействий на несплавные омические контакты с эпитаксиально-доращиваемым сильнолегированным $\mathrm{GaN}$ к гетероструктурам $\mathrm{AlGaN} / \mathrm{GaN}$ наилучшую термостабильность показал состав металлизации $\mathrm{Cr} / \mathrm{Pd} / \mathrm{Au}$, позволяющий использовать этот состав без изменения контактного сопротивления до температуры $400^{\circ} \mathrm{C}$, являющейся максимально используемой в технологическом цикле изготовления СВЧ МИС. Для всех исследуемых композиций состава металлизации было замечено изначальное увеличение значения удельного контактного сопротивления, но 
после 400-500 ${ }^{\circ} \mathrm{C}$ происходило его незначительное уменьшение по отношению к первоначальному значению. Так же для омического контакта к гетероструктуре с ДЭГ с составом металлизации $\mathrm{Cr} / \mathrm{Pd} / \mathrm{Au}$ было установлено, что при нагреве свыше $400^{\circ} \mathrm{C}$ на фоне улучшения общего контактного сопротивления происходит деградация контактного сопротивления металл-полупроводник за счет миграции золота в сторону полупроводника через диффузионный барьер (Pd). Эффект уменьшения контактного сопротивления к ДЭГ при температурах выше $400^{\circ} \mathrm{C}$ был не прогнозируемым, так как в зарубежной литературе в основном исследовалась деградация несплавных омических контактов, сформированных непосредственно на сильнолегированном GaN.

Работа выполнена при финансовой поддержке Министерства образования и науки РФ (соглашение о предоставлении субсидии № 14.607.21.0124, уникальный идентификатор проекта RFMEFI60715X0124).

\section{Список литературы}

[1] Федоров Ю.В., Гнатюк Д.Л., Бугаев А.С. и др. // Микроэлектроника. 2016. T. 45. B. 2. C. $135-143$.

[2] Михайлович С.В., Галиев Р.Р., Зуев и др. // Письма в ЖТФ. 2017. Т. 45. В. 16. C. 9-14.

[3] Павлов В.Ю., Павлов А.Ю. // Нано- и микросистемная техника. 2016. Т. 18. B. 10. C. $635-644$.

[4] Lee M.L., Sheu J.-K., Hu C.C. // Appl. Phys. Lett. 2007. V. 91. P. 182106.

[5] Chang Z., Shu-Ming Z., Hui W. et al. // Chin. Phys. Lett. 2012. V. 29. N 1. P. 017301.

[6] Павлов В.Ю., Павлов А.Ю., Слаповский Д.Н. и др. // Тез. докл. 11-й Всерос. конф. „Нитриды галлия, индия и алюминия - структуры и приборы“. 2017. C. $132-133$.

[7] Арутюнян С.С., Павлов А.Ю., Павлов В.Ю. и др. // ФТП. 2016. Т. 50, В. 8. C. $1138-1142$.

[8] Guo J., Li G., Faria F. et al. // IEEE Electron Device Lett. 2012. V. 33. N 4. P. 525-527.

Письма в ЖТФ, 2017, том 43, вып. 22 